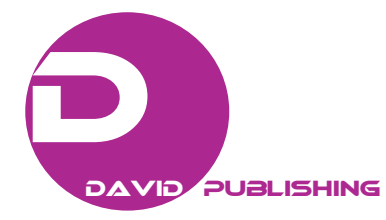

\title{
Climate Change Impacts on Water Resources of Ary Creek, Inverloch, Victoria
}

\author{
Sultana Nasrin Baby ${ }^{1}$, Colin Arrowsmith ${ }^{1}$, Nahla Abbas ${ }^{2}$ and Nadhir Al-Ansari ${ }^{3}$ \\ 1. School of Mathematical and Geospatial Sciences, Royal Melbourne Institute of Technology (RMIT University), GPO Box 2476, \\ Melbourne VIC 3001 Australia \\ 2. School of Engineering and Technology, Central Queensland, University, Melbourne, Brisbane, Queensland 4000 Australia \\ 3. Lulea University of Technology, Lulea 971 87, Sweden
}

\begin{abstract}
Understanding urban wetland ecosystem services structure allows managers to base restoration efforts on multiple user end-benefits. Ary Creek can provide the coupled function of improving water quality and mitigating floods through delayed stormwater flow. It is fundamental to identify areas surrounded by water for the safety of individual should in case the water level raise beyond a reasonable doubt and might cause a flood. For many years, the Ary Creek catchment in Inverloch has been flooding and causing great problems for the inhabitants as well as the environment. The procedure is to develop models of the area around the catchment or watershed using Victorian Coastal LiDAR and other input data from the GIS (geographic information system). This study uses the real-time simulation in ArcSWAT-ArcGIS 10.3 and 3D in ArcScene 10.3, and the variables obtained from the soil and water assessment tool ArcSWAT such as the land use, soil and slope are the parameters measured to induce the flood. When certain portions of the Hydrologic response unit HRU, land use, soil or slope is changed due to temporal adjustment and climate change, then the model can predict zones of low, moderate and high flood risk. The 3D simulations appear to produce a visual model for decision-making, planning, management, and mitigation. The simulation helps in determining the extent of the flood by using animation.
\end{abstract}

Key words: Modelling, flood, simulation, LiDAR, GIS, ArcSWAT.

\section{Introduction}

According to Lin et al. [1], flood can be defined as a high water flow naturally or artificially from the river bank that dominates the surrounding area to cause overflow. The high flow of the water may extend over the floodplain and generally become a hazard to the society. Flood is one of the devastating hazard or disasters that Victoria had been experiencing over the decades. There is a problem of flash flood in the Ary creek watershed particularly during monsoon period (November to February) every year, but more severe in 2011, 2012 and 2013 (Tables 1 and 2).

According to Zhang et al. [2], SWAT is increasingly being used in the watershed hydrological processes widely accepted and understood for evaluation of

Corresponding author: Nadhir A. Al-Ansari, professor, research fields: water resources and environment. modelling application. Javier et al. [3] have explored the degree of complexity on spatial variables in the watershed on examination of parameters. This is because input data are not only affected by parameters but also modify the inbuilt model structure.

The DELWP (Department of Environment, Land, Water and Planning), is responsible for providing flood forecast and warning services to the public [4]. Land use affects land cover and vice-versa, but changes in land cover by land use do not explain the reason for degradation of land (Fig. 1). However, it denotes shifting land use pattern by various factors of social changes also result in land cover changes that affect ecosystem and biodiversity. Radiation budget and water trace gas emission and other processes which directly affect climate and biosphere [5].

The application of SWAT and the 3D environment has contributed greatly in identifying areas or zones 
Table 1 Total area of the watershed.

\begin{tabular}{llll}
\hline Watershed-Number of Sub-basins & Area [ha] & Area [acres] & Number of HRUs \\
\hline 8 & 132.50 & $13,250.06$ & 14 \\
\hline
\end{tabular}

Table 2 Total area of the watershed, building, sub-basin, runoff and precipitation.

\begin{tabular}{llllll}
\hline Watershed & building_Area & subbasin_Area & runoff2011 & \multicolumn{2}{l}{ sumPRECIPmm2011 avePRECIPmm } \\
\hline 1 & $52,634.91$ & $215,995.80$ & 111.454 & $1,601.8$ & 133.48 \\
2 & $49,970.39$ & $371,605.66$ & 155.372 & $1,601.8$ & 133.48 \\
3 & $26,357.46$ & $128,900.71$ & 264.094 & $1,601.8$ & 133.48 \\
4 & $27,634.52$ & $145,739.08$ & 215.417 & $1,601.8$ & 133.48 \\
5 & $17,178.77$ & $90,578.87$ & 264.017 & $1,601.8$ & 133.48 \\
6 & $38,890.68$ & $225,866.59$ & 143.596 & $1,601.8$ & 133.48 \\
7 & $17,296.50$ & $92,320.78$ & 240.69 & $1,601.8$ & 133.48 \\
8 & $7,569.51$ & $53,998.95$ & 68.807 & $1,601.8$ & 133.48 \\
Grand total & $237,532.74$ & $1,325,006.44$ & $1,463.447$ & $12,814.4$ & 133.48 \\
\hline
\end{tabular}

affected by flood in each sub basin parameter within the Terengganu watershed. The 3D modelling and simulation using the $0.5 \mathrm{~m}$ resolution from the Future Cost liDAR Data DEM (digital elevation model) were converted into ArcScene using ArcGIS-3D software. During the ancient times, people developed ways of monitoring flood level, this enables them to predict the water flow, and the risk or hazard involved. The 3D visualization techniques include the remote sensing, such as satellite imageries, aerial photogrammetric, GIS (geographic information system) and LiDAR modelling. The recent application of 3D GIS had provided clear presentation and visualization of flood hazard event than the previously used of 2D maps [6].

Geographic modelling and simulation are now considered to be fundamental in process and mining as well as dam-break flood. The dam is of benefit to people but there is a tendency to be broken due to flood hazard event [7]. The 3D model display information uses in Google Earth. The KML files will be read in ArcGIS. Google Earth Pro is more advanced than the standard version, which allows high image resolution to be overlaid with other information included in GIS data. It is necessary to analyse water flow direction within two meters that can allow flood monitoring and change it from 2D to 3D [8]. The DEM was used to develop mesh in the system and the water mask was generated for simulation of flood and produce flood models. This can be successfully visualized in the realistic 3D environment [8].

Flood has been affecting human habitat and creating the unsustainable environment. The current study about the event in many cities, towns or villages can never be overemphasized because climatic conditions are not static. The land covers as well as the geographical settings. The GIS will be applied in acquiring spatial and non-spatial data. The river flows are quite high during the monsoon, and the water level becomes high, therefore we create the DEM to simulate the flow direction at regular interval to avoid the flood. We need to get informed or be informed about the aftermath of flood event that is the hazard and damages as quickly as possible, to assess the magnitude of losses and plan for the relief operation.

The 2012 flood resulted from a severe weather event with heavy rainfall and widespread flooding across a number of municipalities. Its impact was made worse by the degree of rainfall and flooding experienced a few weeks earlier that had saturated catchments. Emergency services were also challenged by concurrent windstorms. The report 2012 Gippsland Flood Event-Review of Flood Warnings and Information Systems [9] states that: "For a rapidly escalating event in Gippsland, local resourcing provided very limited capacity and minimal contingency for a protracted event". In the later stages 


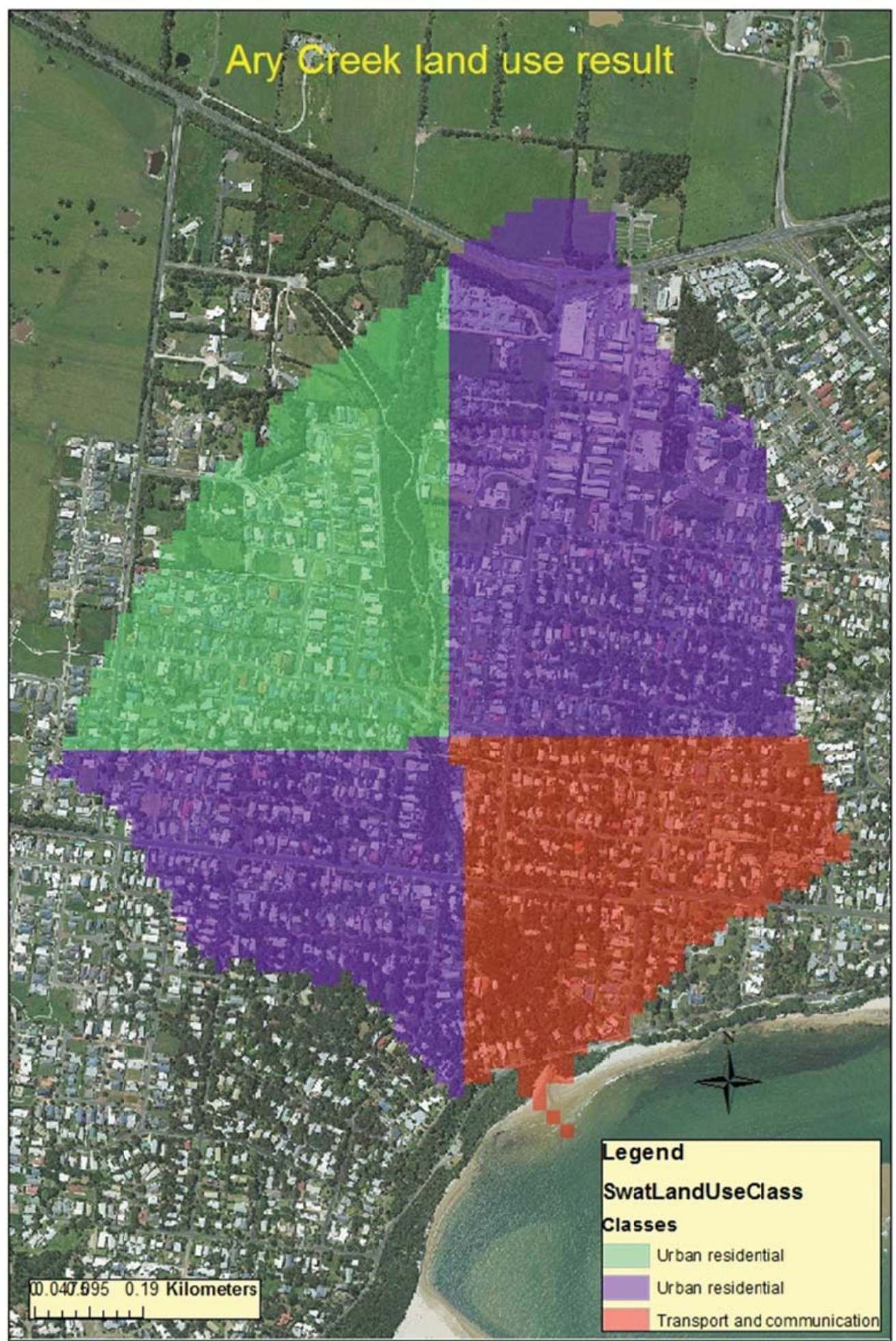

Fig. 1 Land use result. 


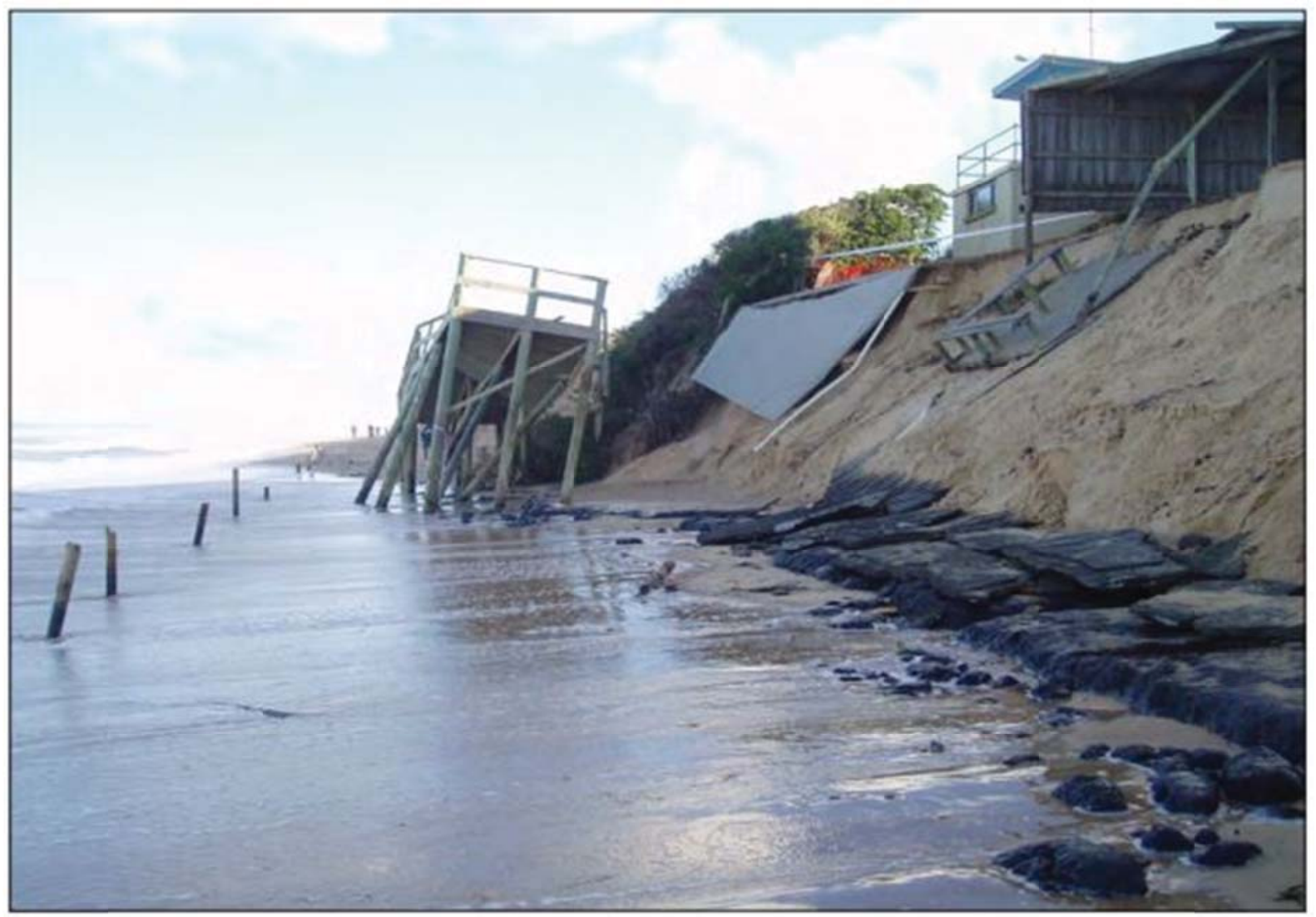

Fig. 2 Coastal damage at Seaspray, 2007 (Source: WGCMA).

of this flood event, personnel from other regions in Victoria reinforced key functions in the ICC (Incident Control Centre). The significant burden imposed by widespread flooding in Gippsland can be managed to some extent by the ability to predict flood risks and consequences across the region, and the potential to focus the dissemination of information about flooding to the wider community and, importantly, target local communities directly affected. The West Gippsland coastline is vulnerable to coastal inundation during significantly high tides, particularly when in conjunction with storm surges. The severity of impacts varies depending on factors including geomorphology, estuary characteristics and population and infrastructure inundated. In addition, the impact of individual meteorological events on flooding can vary due to precedent conditions and the direction and severity of weather conditions. Assets including farmland, roads, boardwalks, life-saving towers, foreshores and jetties have been damaged as a result of coastal inundation. Flood is most severe in hazard in Inverloch-Ary Creek [10]. The issue of flood disaster is a global phenomenon that requires attention in other to control life and properties. There is need to monitor the activities of the flood by applying the modern technology of GIS [11].

\section{Materials and Methods}

\subsection{Study Area}

The study focuses on the flood mitigation in one of the flood-prone Ayr Creek in Inverloch has formed a natural lagoon on the foreshore. This recurring natural phenomenon provides both a thriving environment and ecosystem for birds and aquatic Council met with WGCMA and Environment Protection Authority on-site recently to discuss the odour issue, and experience it first-hand. The WGCMA and Council will begin a joint project to investigate options. The project will engage a qualified specialist and use a 
citizen science approach to help find the balance between the environmental values and amenity issues. This project will include the responsibility of caring for the lagoon and minimising odour issues. Bass Coast Manager Sustainable Environment, Deirdre Griepsma, explained that Anderson Inlet is one of the most dynamic inlets in Victoria with vast natural sand movements and changing currents. These movements form a part of how the lagoon is formed, and how it naturally opens.

"Both the open and closed occurrences are natural and an important part of the estuary cycle; we know that nature will run its course to open the lagoon, unfortunately, we cannot predict when it will happen," Ms. Griepsma said.

Micro-organisms in the lagoon produce nutrients for plants and help to maintain the vital habitat for macroinvertebrates, fish and birds. These micro-organisms breathe in sulphate from salt water, eat organic matter and turn these into nutrients that benefit the environment. A by-product of this process is the hydrogen sulphide odour which is not harmful to humans or animals in the open air but does produce an unpleasant odour.

"The estuary is a habitat to several threatened bird species. Artificially opening the lagoon can result in poor water quality, fish deaths and changes in vegetation and therefore negatively impact the amenity and landscape of the estuary," Mrs. Griepsma said. "For these reasons, we need to be very meticulous in considering how we manage the lagoon." While the lagoon is not unsafe or harmful, Council advises that people should not swim in Ayr Creek or the connected lagoon [12].

\subsection{Flood Prevention Works in Inverloch}

Bass Coast Shire Council is undertaking urgent works to prevent flooding and clear blockages in Ayr Creek drainage reserve in Inverloch. Council will be engaging a number of contractors to help with the works, which are scheduled to start by Monday, 4 May, take up to three weeks depending on weather, and ground conditions. Council's General Manager Infrastructure, Felicity Sist, said the works would include general channel maintenance and flow improvements, urgent waterway maintenance to protect properties in Diane Place from flooding and construction of a permanent levee bank on Diane Place. "These works will protect both private and Council assets from flooding," Ms. Sist said. "We also have permits from the West Gippsland Catchment Management Authority to allow some vegetation clearance in the waterway to allow free flow of drainage water; however any vegetation removal will be kept to a minimum" [12].

\subsection{Methods}

The SWAT data sources are obtained from:

- DID (Department of Irrigation and Drainage);

- Data forflood event in the study area (previously);

- DEM (digital elevation model) data;

- Stream flows data;

- Land cover/land uses data;

- Soil types.

These are obtainable bases on a different location of the stations:

(1) Weather data downloaded from weather observations and climate data from the ADAM (Australian data archive for meteorology) (http://www.bom.gov.au/climate/cdo/about/about-wea ther-data.shtml).

(2) Land covers images from Land use of Australia 2010-11 (https://data.gov.au).

(3) Australian soil map was obtainable from an online source, Digital Atlas of Australian Soils (https://data.gov.au).

\subsection{Required Spatial Datasets and Optional Spatial Datasets}

Required spatial datasets and optional spatial datasets are:

- DEM; 


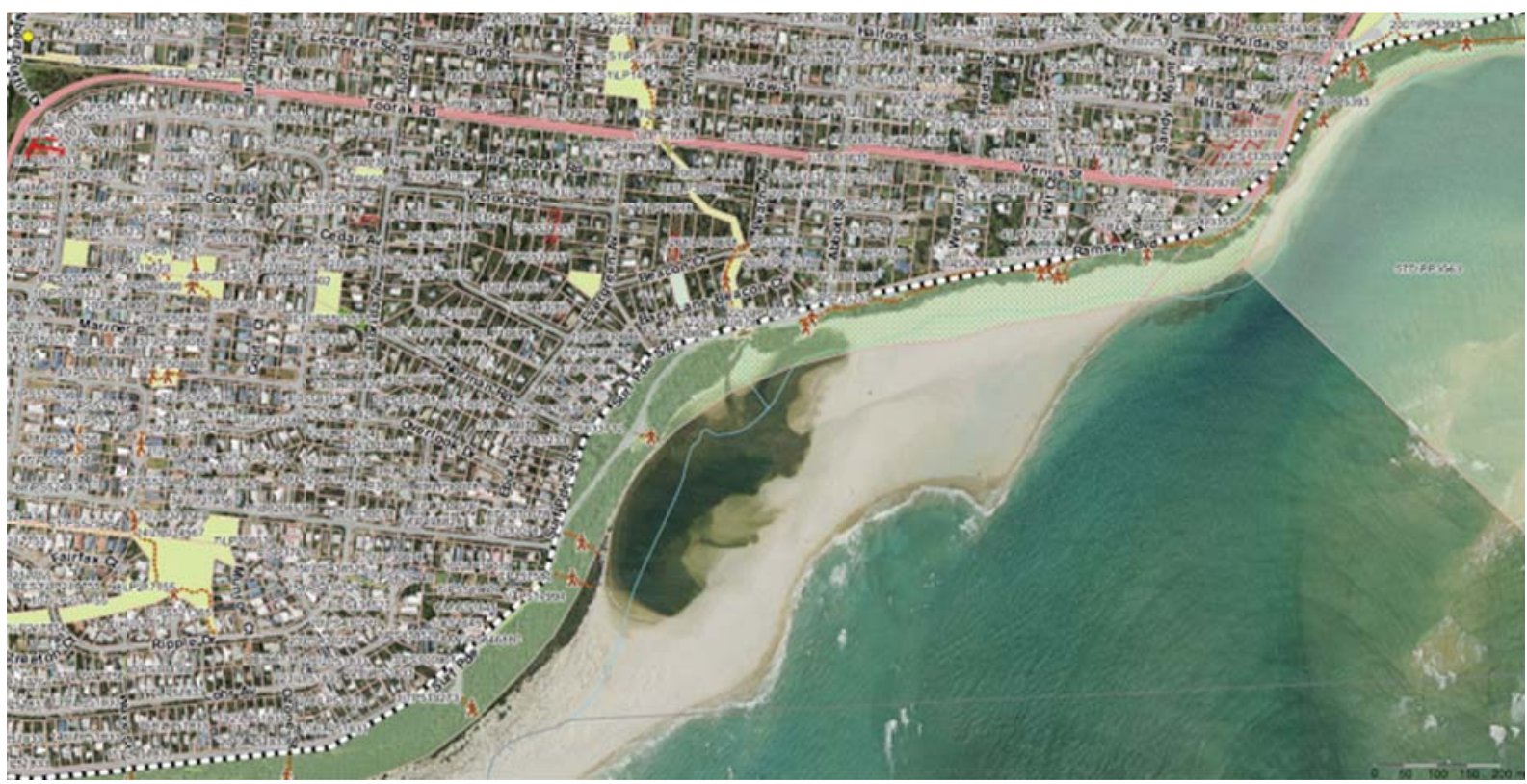

Fig. 3 Bird's eye view of Ayr Creek lagoon (http://news.basscoast.vic.gov.au/ayr-creek).

- Land cover;

- Soil map/data.

The optional spatial datasets include:

- Weather parameters;

- Daily rainfall data;

- Daily stream flow;

- Daily suspended-sediment.

\section{Results and Discussion}

The result from the SWAT was obtained on Date: 6/13/2018 and SWAT model simulation MULTIPLE HRUs Land Use/Soil/Slope OPTION, THRESHOLDS: 10/10/10 [\%], Number of HRUs: 13, Number of Subbasins: 8 were studied, with the total area of the watershed having 132.50 hectares or 13,250.06 acres. The total numbers of sub-basins are 8 characterized by 13 numbers of HRUs (hydrologic response units). The threshold of 10/10/10 percent was chosen and selected. The flood risk event has been overcome by developing real-time simulation in the $3 \mathrm{D}$ scenario. This becomes apparent when the use of GIS was employed to solve the problems of flood risk. This is done through visualization of selected zones affected by flood in Ary Creek (Fig. 5). The results from the SWAT watershed delineation was presented in Fig. 6.
Watershed is also known as a basin or catchment, or simply an area delineated with a specified outlet point that emptied in a large body of water. Fig. 6 represents the delineated watershed of Ary Creek catchment. The stream links and reservoirs are developed through the stream network. Twelve stream links are obtained from the Ary Creek catchment. Each stream link had been connected with the defined sub-basins. There are about eight different sub-basins in the study area selected. Each of the sub-basins was characterized by a distinct parameter for classification and hydrologic analyses. Fig. 6 shows the classified sub-basins in Ary Creek catchment. In the HRU analysis obtained from the SWAT, four major sub-basins were fully discussed. The subbasins number 5 and 8 are selected as the smallest sub-basins in the Ary Creek catchment with 14.45 hectares SWAT area of $10.56 \%$.

The land covers characteristics include residential-low density and transportation. The soils found within the sub-basins are the local soils called LOAMY-SAND and Steep land then the lowest slope has $95.22 \%$ and the highest slope is $4.78 \%$ respectively. Fig. 7 shows the classified slope in Ary Creek catchment. 


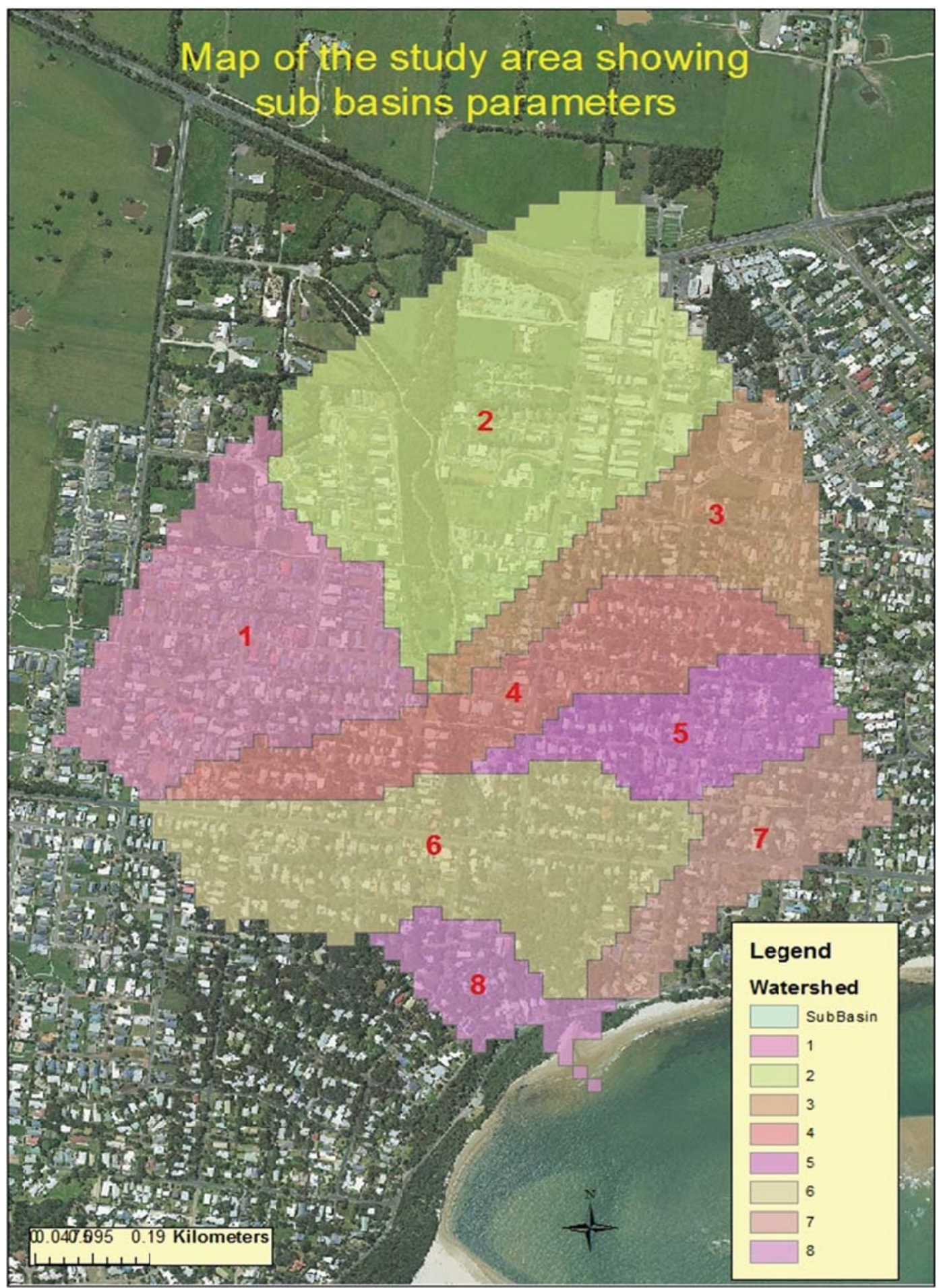

Fig. 4 Study area sub-basins map. 


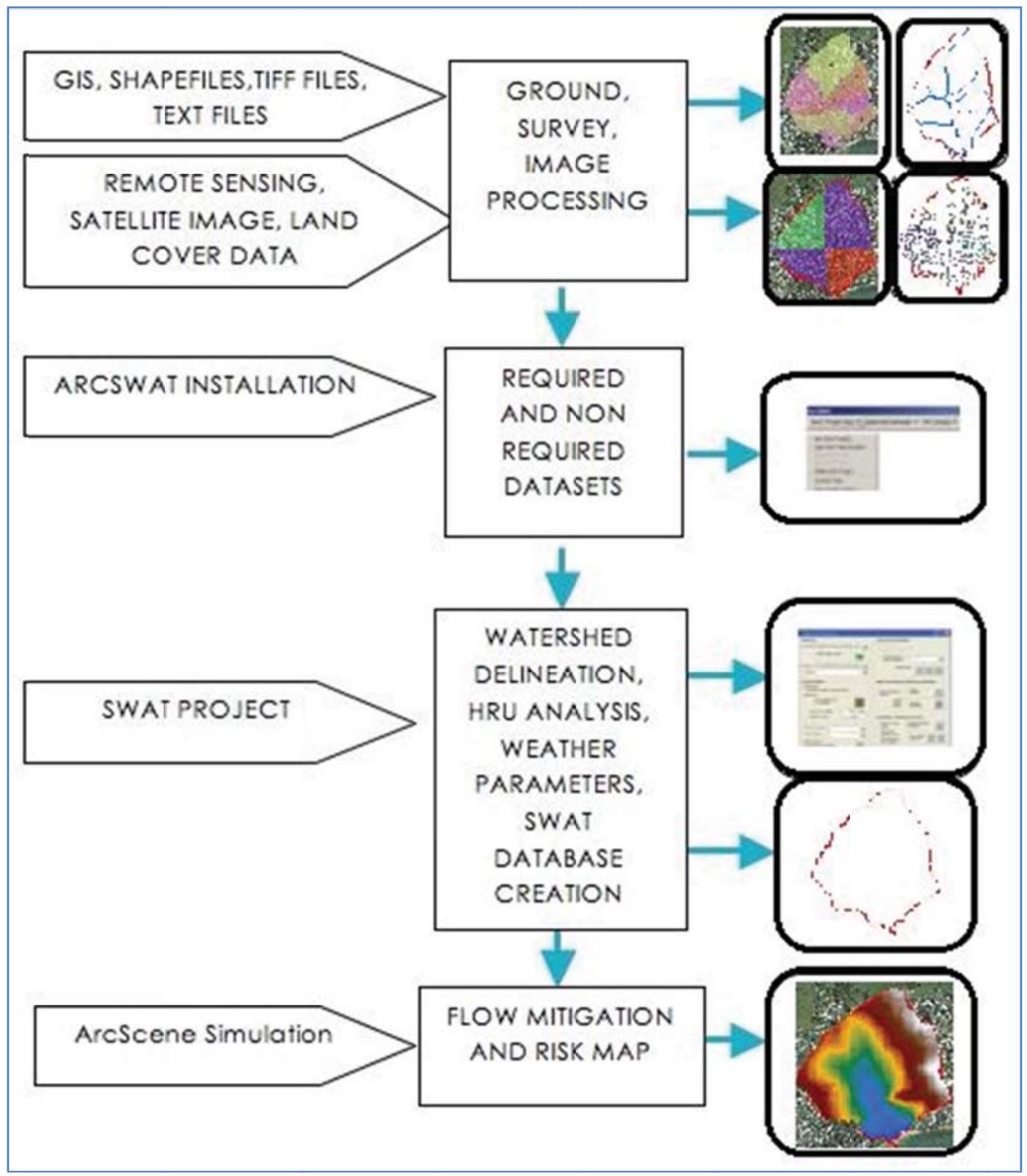

Fig. 5 SWAT flow chart. 


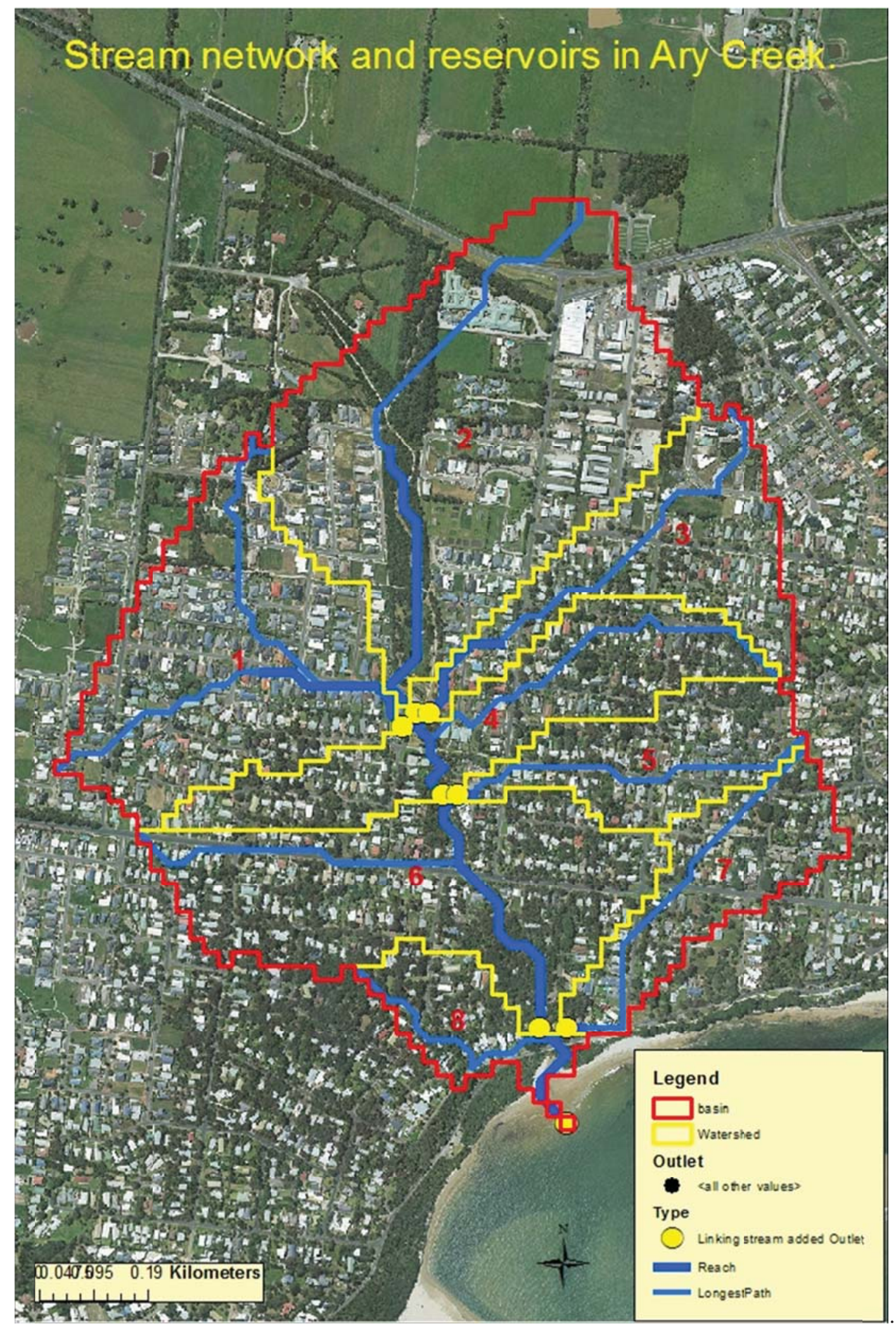

Fig. 6 Watershed delineation, stream network and reservoirs in Ary Creek. 


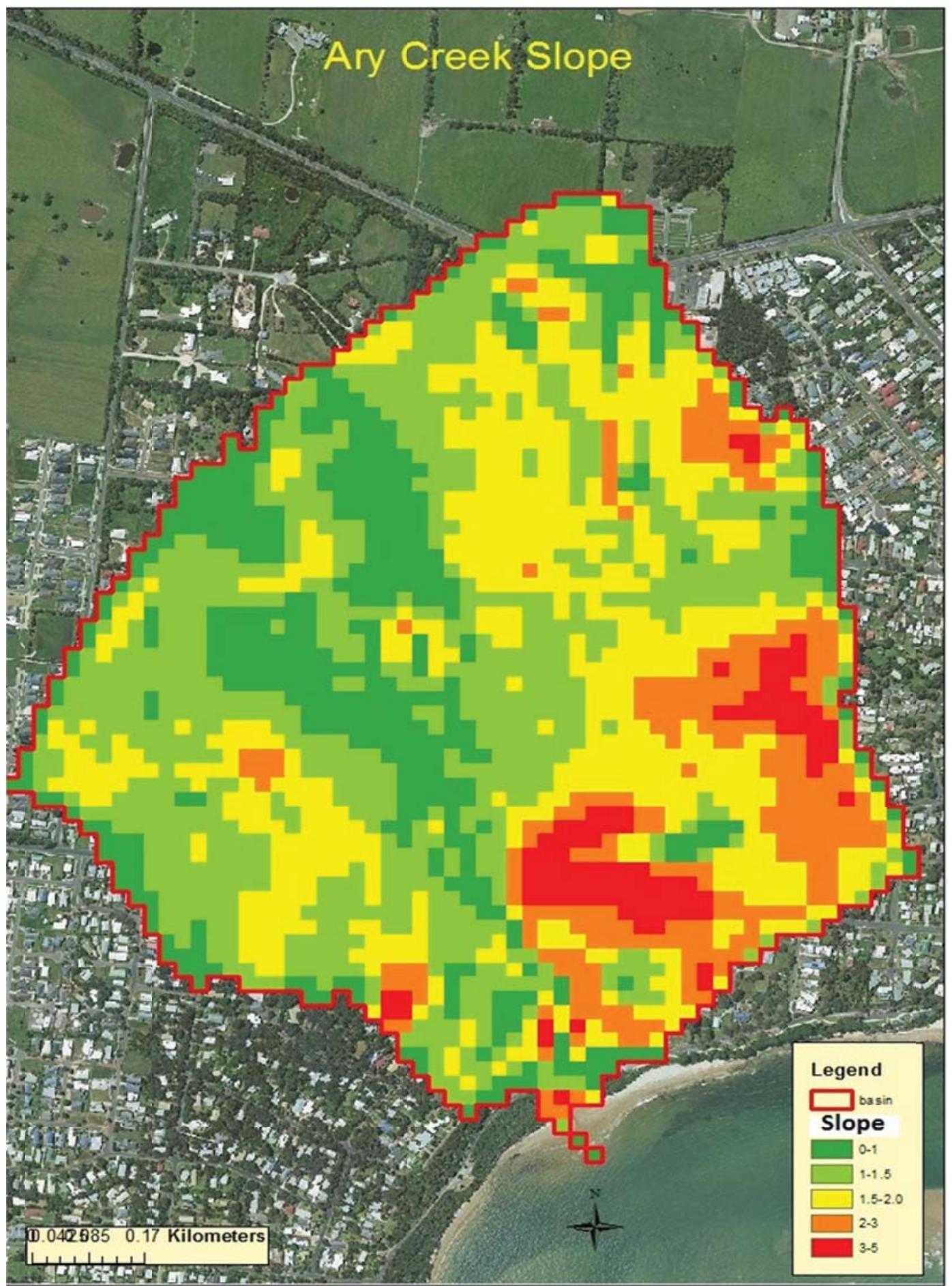

Fig. 7 Ary Creek slope.

Furthermore, the sub-basins number 2 has 37.16 hectares with total SWAT area of $100 \%$ with a land cover of urban residential and water and the local soil type called LOAMY-SAND. From geological point of view, the sediments are mostly of Tertiary and
Pleistocene age forming undulating landforms rises. Apart from soils in drainage depressions, the surface soils range from very dark grey clay loams to gravelly loams and occasionally loamy sand. This overlies a light grey or light brownish grey similarly textured 
subsurface soil at about $20 \mathrm{~cm}$. Below the bleached zone, the subsoils are quite variable. The largest sub-basins found in the catchment area of Ary Creek are the sub-basins number 2 and 6. The total area in subbasin 2 is 37.16 hectares with SWAT area of 28.04\%; the land covers include the 192 building and total building area 53,989.66 sqm (Table 3).

The below explains the different pattern of the land cover which includes forest, water, urban land use, rubber paddy orchard oil palm, and grassland. The soils classification was based on the United States Geological Survey (USGS) with default SWAT soil database. The local soils in the study area are edited base on the SWAT update from the existing soils of the world. Table 4 shows the result of the slop classification with total areas in hectares, acres as well as the total per cent obtained during the analysis (Fig. 7).

The soils have the ability to absorb moisture and get cooler and hotter quickly. Depending on the temperature, the water retention capacity varies from equatorial wet climate to monsoon as well as arid and semi-arid environment. The steep land has the highest percentage of $61.23 \%$. However, it is most likely to have less water retention capacity.

The slope data derived from the SWAT database was an inbuilt developed from the threshold of 10/10/10 percent from the HRU. Table 4 shows the result of total area from each category of slope in hectares and acres while taking cognizance of slope percent from 0-10 up to 40 meters above.

The elevation or slope map of the Ary Creek catchment shows dark grey colour depicts the lowest elevation that is 0-10 meters. The green colour pattern is 10-20 meter slope, the blue colour is between 20-30 and lastly, the light grey colour in the map represents the highest slope.

Flood risk and mitigation model was developed as shown in Fig. 8. The yardstick is to measure the magnitude of the flood risk in the catchment area of Ary Creek. Here we arrived at the categories of flood risk from the highest risk to moderate and no risk zones within the watershed. The flood risk map represents the risk zones which can be used for mitigation, planning, and a warning to the public.

The removal of major land cover such as previous land cover in Ary Creek will significantly affect the zones which are predominantly occupied by the creek. While both zones are at flood risk, the presence or absence of more land covers will ultimately change the water flow. The aftermath of flood event usually is associated with pollution. Dirty water with refuse and garbages, as well as blocked drainages, might cause an outbreak of epidermal disease, the risk of lives through broken cables can easily electrocute humans and live animals.

Table 3 Total pervious and impervious.

\begin{tabular}{lll}
\hline Years & 2012 & $\%$ \\
\hline Basin & $1,325,006.43$ & \\
Building & $237,532.74$ & 17.92 \\
Road & $113,088.64$ & 8.53 \\
Total impervious (building, road) & $350,621.38$ & 26.45 \\
Total pervious area & $623,763.67$ & 73.55 \\
\hline
\end{tabular}

Table 4 Slope result.

\begin{tabular}{llll}
\hline GRIDCODE & Area $(\mathrm{SQ})$ & Area $($ ha $)$ & \%wat. area \\
\hline 0 & $268,404.64$ & 26.84 & 20.39 \\
1 & $800,183.64$ & 80.2 & 61.23 \\
2 & $189,022.49$ & 18.2 & 13.83 \\
3 & $50,650.26$ & 5.07 & 3.58 \\
4 & $11,592.61$ & 1.16 & 0.88 \\
5 & $1,161.27$ & 0.12 & 0.09 \\
\hline
\end{tabular}




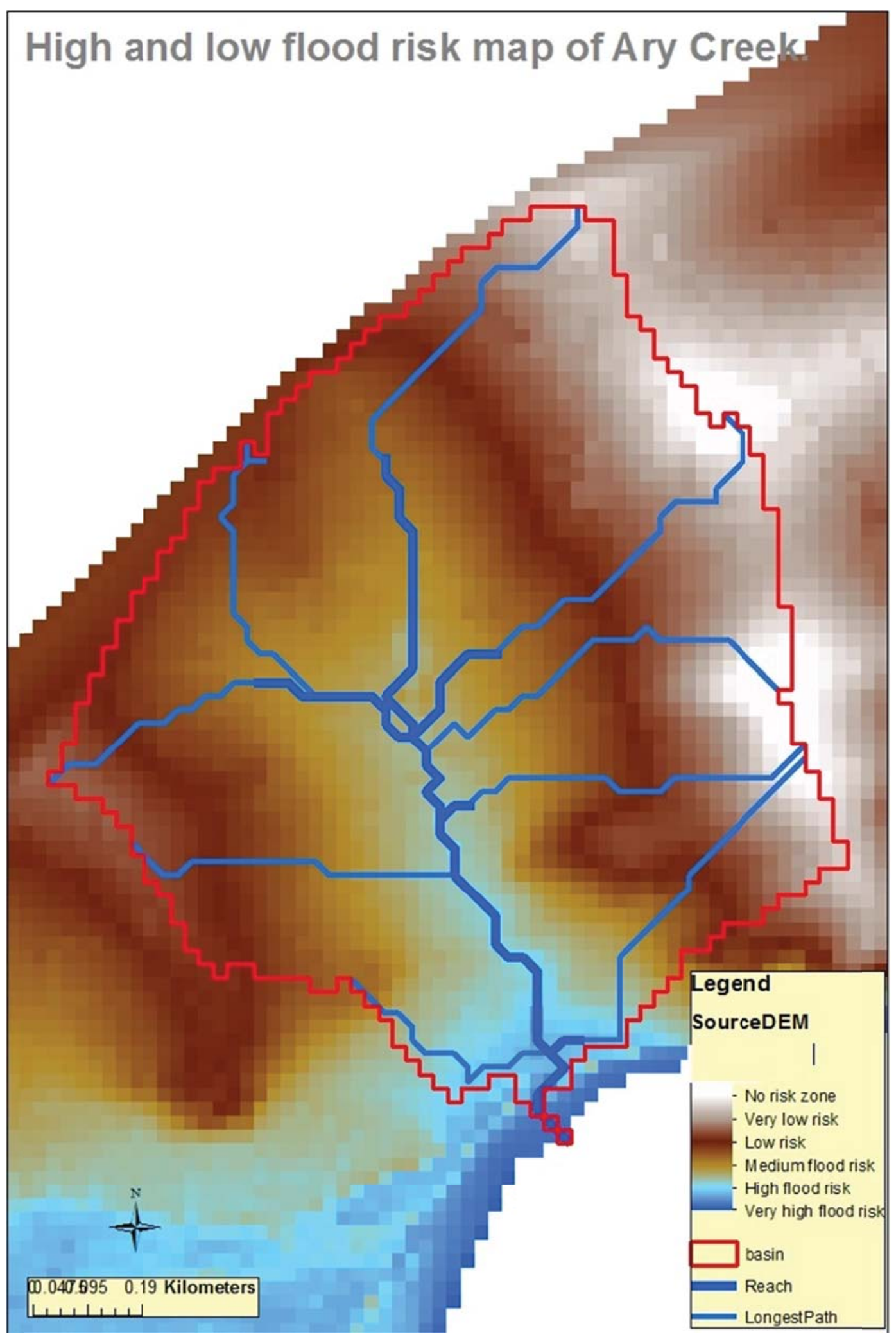

Fig. 8 High and low flood risk of Ary Creek catchment. 


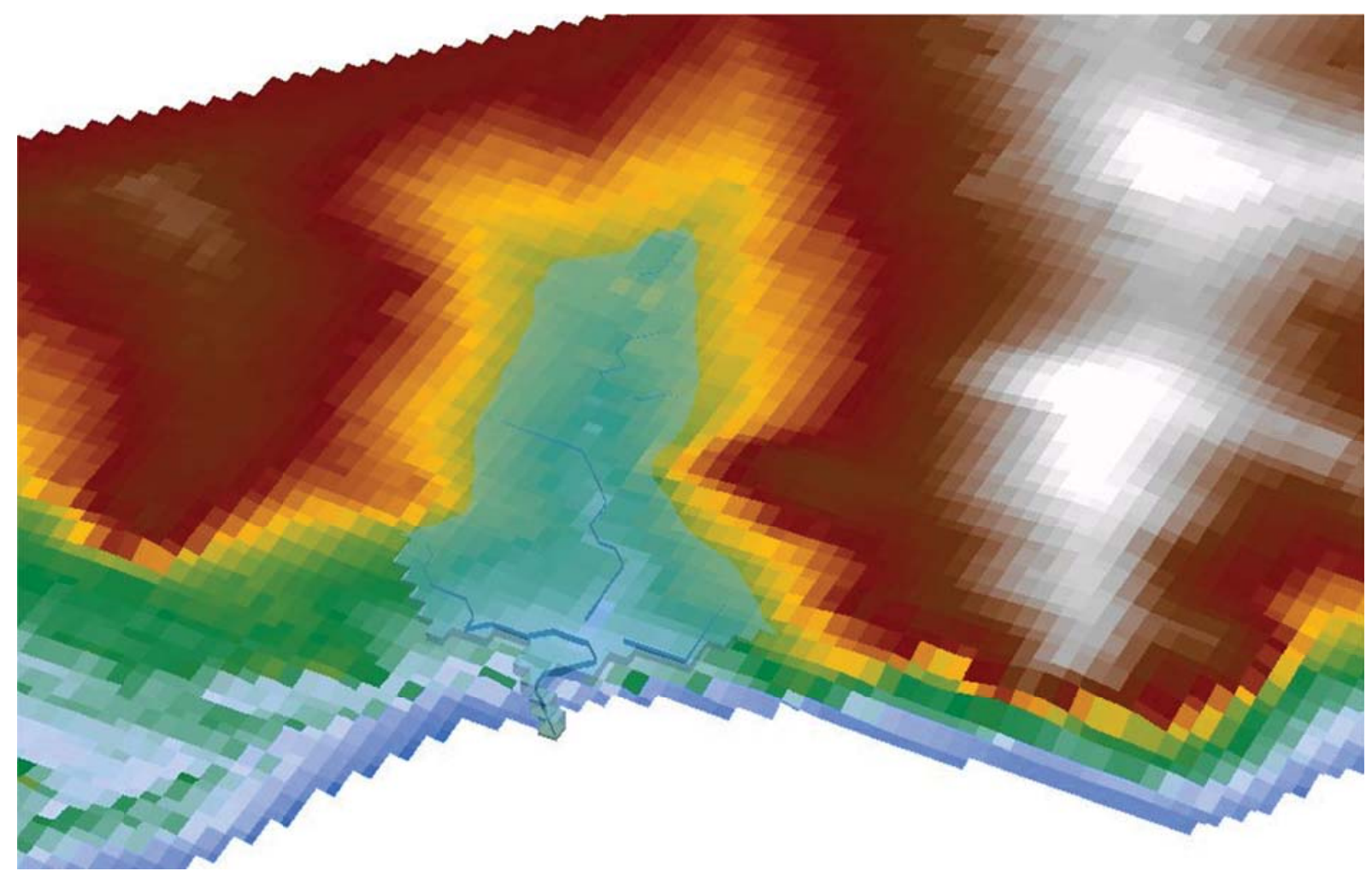

Fig. 9 3D flood simulation model of Ary Creek catchment.

The 3D flood models were produced from DEM of the study area which was overlaid with the mask and the Ary Creek flow was considered as a base height. Fig. 9 describes the 3D model developed by the ArcScene. At this point, the $\mathrm{Z}$ values are calculated in other to create the simulation. The real-time simulation is presented in Fig. 9 while the simulation was displayed, the purpose is to create a quick alert or warning through animation video perhaps all the areas prone to flooding will be easily identified and mitigation action can be applied.

Flood simulation model of Ary Creek catchment in Fig. 9 presents the real-time 3D simulation with the blue colour representing the flood event that ranges from 0 to 30 meters of elevation while other zones from 20 to 30 meter will be a flood if the water level increases. The model is also available in animated form.

\section{Conclusion}

The study of flood simulation becomes paramount in other to evaluate and provide information for decision making and flood control planning. At present, the $2 \mathrm{D}$ visualizations are not sufficient in presenting real scene and therefore cannot make a full representation of data available. Today geographical 3D simulation and modelling are regarded as a fundamental approach to solving complex geographic problems. The SWAT has developed the scenario from the individual sub-basins for the Terengganu catchment where about 25 sub-basins parameters are obtained in the catchment. The watershed has been delineated and creates sub-basins parameters where each sub-basin is having distinct characteristics of HRU. The recent trend in flood monitoring was applied to $3 \mathrm{D}$ for the quick response, alert and warning, mitigation, planning, and management. Each time there is a flood in Terengganu we can visualize its base on the predicted simulation in $3 \mathrm{D}$. The research is vital to urban planners, surveyors, environmentalist as well as engineers and geologists.

\section{References}

[1] Lin, G. F., Chou, Y. C., and Wu, M. C. 2013. "Typhoon 
Flood Forecasting Using Integrated Two-Stage Support Vector Machine Approach.” J Hydro 486: 334-42.

[2] Zhang, X., Srinivasan, R., and Hao, F. 2007. "Predicting Hydrologic Response to Climate Change in the Luohe River Basin Using the SWAT Model." Transactions of the ASABE 50: 901-10.

[3] Javier, J. R. N., Smith, J. A., Meierdiercks, K. L., Baeck, M. L., and Miller, A. J. 2007. "Flash Flood Forecasting for Small Urban Watersheds in the Baltimore Metropolitan Region.” Wea Forecast 22: 1331-44.

[4] Mulcahy, S., and Schroen, J. 1993. "Target 10 Irrigation and Drainage Reference Manual." Research paper, Department of Agriculture, Victoria, Melbourne.

[5] Riebsame, W. E. W. E., Meyer, W. B., and Turner, B. L. 1994. "Modelling Land Use and Cover as Part of the Global Environmental Change." Clime Change 28: 45-64.

[6] Chan, N. W. 2015. "Impacts of Disasters and Disaster Risk Management in Malaysia: The Case of Floods." Resilient Recove Asian Disast 24: 239-65.

[7] Hossain, A. K. M. A., Jia, Y., Ying, X., Zhang, Y., and Zhu, T. T. 2011. "Visualization of Urban Area Flood Simulation in the Realistic 3D Environment." World Environmental and Water Resources Congress 1: 1973-80.
[8] Liu, Y. B., Gebremeskel, S., De Smedt, F., Hoffmann, L., and Pfister, L. 2003. "A Diffusive Transport Approach for Flow Routing in GIS-based Flood Modelling." J Hydrol 283: 91-106.

[9] Office of the Emergency Services Commissioner, Department of Justice Victoria. 2012. Emergency Management Act 2013, No. 73 of 2013. Accessed November, 2018. http://www.legislation.vic.gov.au/ Domino/Web_Notes/LDMS/PubStatbook.nsf/f932b6624 1ecf1b7ca256e92000e23be/81C9131F342CA6E0CA257 C36000F8125/\$FILE/13-073abookmarked.pdf.

[10] West Gippsland Catchment Management Authority (WGCMA). 2017. West Gippsland Floodplain Management Strategy 2018-2027. Available at: https://wgcma.vic.gov.au/wp-content/uploads/2016/08/W GCMA-FloodplanMan-final-FULL.pdf.

[11] Wang, F., and Xu, Y. J. 2008. "Development and Application of a Remote Sensing-based Salinity Prediction Model for a Large Estuarine Lake in the US Gulf of Mexico Coast." J Hydrol 360: 184-94.

[12] Bass Coast Shire Council-BCSC. 2017. Annual report. http://www.basscoast.vic.gov.au/Council/NewsAndPubli cations/Annual_Reports/2017-18. 